\title{
Multilayered Films Produced by Layer-by-Layer Assembly of Chitosan and Alginate as a Potential Platform for the Formation of Human Adipose-Derived Stem Cell aggregates
}

\author{
Javad Hatami ${ }^{1,2,+}$ (D), Sandra G. Silva ${ }^{1,2, \ddagger}$, Mariana B. Oliveira ${ }^{1,2,+}$, Rui R. Costa ${ }^{1,2}$ (D), \\ Rui L. Reis ${ }^{1,2}$ and João F. Mano ${ }^{1,2, t, *}$ \\ 1 3B's Research Group, Biomaterials, Biodegradables and Biomimetics, University of Minho, \\ Headquarters of the European Institute of Excellence of Tissue Engineering and Regenerative Medicine, \\ Avepark-Parque de Ciência e Tecnologia, Zona Industrial da Gandra, 4805-017 Barco GMR, Portugal; \\ jhatami@ua.pt (J.H.); sg82silva@gmail.com (S.G.S.); mboliveira@ua.pt (M.B.O.); \\ rui.costa@dep.uminho.pt (R.R.C.); rgreis@dep.uminho.pt (R.L.R.) \\ 2 ICVS/3B's, PT Government Associated Laboratory, Braga/Guimarães, Portugal \\ * Correspondence: jmano@ua.pt; Tel.: +351-234-370-733; Fax: +351-234-401-470 \\ + Current address: Department of Chemistry, CICECO—Aveiro Institute of Materials, University of Aveiro, \\ 3810-193 Aveiro, Portugal \\ $\ddagger$ Current address: LAQV/REQUIMTE, Department of Chemistry and Biochemistry, Faculty of Science, \\ University of Porto, Rua do campo Alegre s/n, 4169-007 Porto, Portugal
}

Received: 10 August 2017; Accepted: 6 September 2017; Published: 13 September 2017

\begin{abstract}
The construction of multilayered films with tunable properties could offer new routes to produce biomaterials as a platform for 3D cell cultivation. In this study, multilayered films produced with five bilayers of chitosan and alginate (CHT/ALG) were built using water-soluble modified mesyl and tosyl-CHT via layer-by-layer (LbL) self-assembly. NMR results demonstrated the presences of mesyl $(2.83 \mathrm{ppm})$ and tosyl groups $(2.39,7.37$ and $7.70 \mathrm{ppm})$ in the chemical structure of modified chitosans. The buildup of multilayered films was monitored by quartz-crystal-microbalance (QCM-D) and film thickness was estimated using the Voigt-based viscoelastic model. QCM-D results demonstrated that CHT / ALG films constructed using mesyl or tosyl modifications (mCHT/ALG) were significantly thinner in comparison to the CHT/ALG films constructed with unmodified chitosan $(p<0.05)$. Adhesion analysis demonstrated that human adipose stem cells (hASCs) did not adhere to the mCHT/ALG multilayered films and formed aggregates with sizes between ca. 100-200 $\mu \mathrm{m}$. In vitro studies on cell metabolic activity and live/dead staining suggested that mCHT/ALG multilayered films are nontoxic toward hACSs. Multilayered films produced via LbL assembly of ALG and off-the-shelf, water-soluble modified chitosans could be used as a scaffold for the 3D aggregates formation of hASCs in vitro.
\end{abstract}

Keywords: layer by layer assembly; chitosan; alginate; cytotoxicity; multilayered film; adhesion; 3D culture; spheroid

\section{Introduction}

Mesenchymal stem cells (MSCs), which are capable of self-renewal and multilineage differentiation, are becoming increasingly important for the development of cell therapeutics in regenerative medicine. Adipose-derived stem cell (ASC) represents a very attractive cell type of MSCs that are easily accessible, abundant and rich source of adult stem cells [1]. ASCs are able to self-replicate and can differentiate into osteogenic, adipogenic, and chondrogenic lineages under 
specific conditions [2]. These potentials, along with their easy accessibility, made ACS a good candidate for many cell-based therapies. The stem cell niche and its microenvironment have important effects on the function and biology of stem cells [3]. For example, the cellular phenotype and biological response of cells are different in a monolayer and 3D culture [4]. Approaches providing a 3D culture environment are becoming popular for cell cultures because they mimic in vivo condition. It was demonstrated that aggregates of bone-marrow-derived MSCs could have therapeutic potential [5,6]. ASCs could represent an ideal candidate for a 3D culture of MSCs because of their abundant autologous cells and the ease of their access. Different techniques, such as non-adherent culture condition, nutrient deprivation, air-liquid surface, spinner flask and hanging drop, have been used to form 3D spheroids $[4,6,7]$.

The layer-by-layer (LbL) deposition of materials by electrostatic assembly has often been used to modify the surface of several materials [8-10]. This technique has seen application in the construction of nanostructured and easily tailorable two-dimensional and three-dimensional self-standing structures [11]. Due to its compatibility with the construction of highly organized materials and its high versatility, the LbL deposition method was used for the building of new biomaterials and has seen promising applications in biological field [11,12].

Developing a natural-based multilayer film with tunable size and properties has many applications in the healthcare field [11]. A wide plethora of synthetic and natural origin polyelectrolytes were used as building blocks for LbL construction [13-15]. The use of synthetic polymers allows precise control of the polymers' physicochemical properties, such as molecular weight, while working with low batch-to-batch variation. Moreover, the properties of the polymers may be controlled to withstand a large range of processing parameters, including ionic strength and $\mathrm{pH}$ values of assembly, and their chemical modification is usually easily achievable. The main reason for the great potential shown by natural-origin polymers in the biomedical field is their chemical similarity with the native animal extracellular matrix (ECM) [16,17]. Moreover, a great part of such polymers shows a biodegradable behavior and, importantly for electrostatic-driven LbL assembly, most of them are ionizable (i.e., they are polyelectrolytes) [18].

Polysaccharides are an interesting type of polymers found in nature. They often allow high degrees of hydration, are biocompatible, and are often biodegradable $[15,16,19,20]$. Polysaccharides extracted from marine sources are a particular case of these polymers [16,21], which have seen application in the construction of LbL films. Alginate (ALG), chitosan (CHT), chondroitin sulfate and carrageenans are examples of polysaccharides that have found an application in the construction of nanostructured coatings in two-dimensional materials, self-standing micrometric membranes and three-dimensional structures as hollow tubes, capsules for drug release or cell encapsulation, and scaffolds [22-26]. This array of works supported the wide applicability of such polyelectrolytes, and enhanced their added-value, by incorporating these materials in high-end technological approaches.

ALG and CHT are two marine-origin polysaccharides with high applicability in the development of biomaterials. ALG is extracted from brown algae and regularly used for cell encapsulation as it is well-known for its lack of cell toxicity $[27,28]$. CHT is a cationic polyelectrolyte which may be extracted from different sources including shells of crustaceous. Its popularity in the biomedical field is related with its immunological, antibacterial and wound healing properties [29]. Moreover, CHT shares structural similarities with many Glycosaminoglycans (GAGs) present in native ECM [30]. The chitosan/alginate (CHT/ALG) polyelectrolyte pair has been used to construct LbL-based coatings on several materials [31] and a wide plethora of self-standing structures [11,32,33]. The nanostructured multilayered films obtained from the LbL assembly of CHT/ALG polymers are well-characterized regarding thickness variations, permeability to gases and glucose, mechanical properties and cellular response [23]. Importantly, the properties of this system can be modulated by varying LbL deposition conditions including $\mathrm{pH}$, during deposition, and ionic strength. The films may also be post-processed by the chemical or ionic crosslinking of both components, which affects some system's properties, including their mechanical performance and ability to sustain cell adhesion $[23,24]$. 
The application of multilayered films using LbL deposition of CHT/ALG in biological filed is limited because it requires the use of acidic $\mathrm{pH}$ values due to the insolubility of $\mathrm{CHT}$ in water, at the neutral $\mathrm{pH}$. Martins et al. [34] suggested the use of a water-soluble, commercially available chloride-salt chitosan to prepare CHT/ALG films via LbL assembly in water-soluble conditions, at a neutral $\mathrm{pH}$ in order to extend the application of CHT/ALG film in biological fields. Although that work opened up the possibility of processing CHT/ALG films in water-soluble conditions, the modification of CHT with an inorganic salt limits the use of characterization methods, such as NMR, for the full characterization of the modified chitosan. As an example, the presence of the pick of inorganic salt of $\mathrm{CHT}$ in NMR spectra interferes with the detection of the degree of substitution of CHT.

In the current work, we suggest the use of multilayered films produced by LbL assembly of mCHT/ALG for spheroid formation of hACSs. Therefore, two chitosan derivatives, prepared by chemoselective functionalizing as an amino group of parent chitosans, were used as cationic polyelectrolyte for LbL construction of multilayered films. Two different synthetized modified chitosans (mCHT) with mesyl and tosyl organic salts were obtained. These modifications conferred chitosan with water and organic solvent (e.g., dimethyl sulfoxide) solubility [35]. Moreover, the use of organic medium resulted in a well-controlled and regioselective modification leading to homogenous products that the degree of modification of CHT could be monitored by NMR. We hypothesized that the modification of chitosan with organic salts, due to their chemistry or size, could tailor the properties of the LbL films. This strategy would allow working with off-the-shelf water-soluble chitosans that could be selected prior to the film deposition according to the desired properties of the film, such as its thickness and viscoelasticity. Though chemoselective functionalizing of chitosan was reported previously for different purposes [36,37], the current work demonstrated the possibility to construct LbL multilayer films and to tailor its thickness and viscoelastic properties using water-soluble modified chitosan with organic salt and alginate polymers for the first time, to the knowledge of the authors, as a supporting scaffold for the 3D culture and aggregate production of hASCs. This approach could be interesting for the immediate adaptation of the properties of the films by maintaining their processing conditions, while simply adjusting the type of chitosan used for their construction, in a user-friendly approach.

\section{Materials and Methods}

\subsection{Chitosan Purification, Modification and Analysis by ${ }^{1} H N M R$}

CHT of medium molecular weight (MMW-CHT, $M_{\mathrm{W}}=190-310 \mathrm{kDa}, 75-85 \%$ degree of deacetylation, viscosity 200-800 cP) was purchased from Sigma-Aldrich (St. Louis, MO, USA). CHT was purified by a sequential filtration and precipitation steps in distilled water, sodium hydroxide and ethanol, as described previously [38], followed by freeze-drying. It was then grounded and stored as a powder until further usage.

Chitosan derivatives were obtained by chemoselective functionalizing as an amino group of parent chitosans. In this work, two organic acids were used to modify the chitosan according to a previously reported method [37]. The result of chitosan modification with these organic acids, methanosulfonic and $p$-toluenosulfonic acids, were mesyl-CHT and tosyl-CHT, respectively (Scheme 1). Briefly, methanosulfonic acid or $p$-tolunesulfonic acid monohydrate was added (1:1), drop-by-drop at $10^{\circ} \mathrm{C}$, to a suspension of pre-purified MMW-CHT until clear homogeneous solutions were obtained. The solutions were then stirred for $2-4 \mathrm{~h}\left(10^{\circ} \mathrm{C}\right)$ then washed several times with acetone, to precipitate the salts, and diethyl ether and then, dried in a vacuum oven at $25^{\circ} \mathrm{C}$ for $8 \mathrm{~h}$. Before use, the materials were dissolved in distilled water and freeze-dried. The corresponding salts (mesylates and tosylates), which derived from organic acid, was detected by ${ }^{1} \mathrm{H}$ NMR (Bruker Avance III operating at $400 \mathrm{MHz}$, Billerica, MA, USA) through the peaks of the organic anion. To perform NMR analysis, the samples were prepared in $\mathrm{D}_{2} \mathrm{O}$ in the concentration range of $10-15 \mathrm{mg} / \mathrm{mL}$. All the reagents and solvents (p.a. quality) used in the preparation of mCHTs were purchased from Sigma. 
A

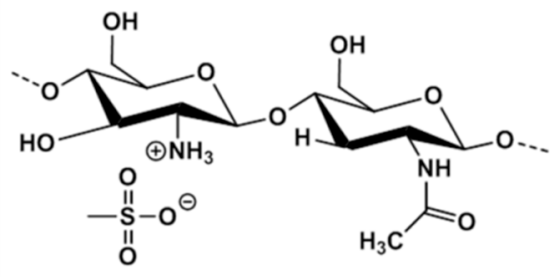

B

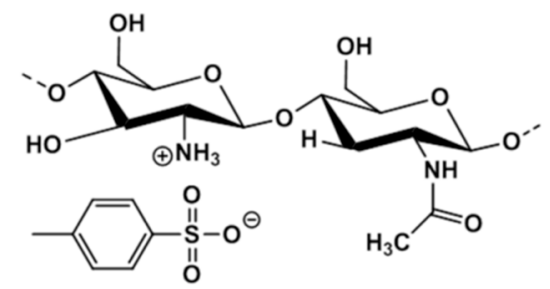

Scheme 1. Chemical structure of mesyl-chitosan (CHT) (A) and tosyl-CHT (B).

\subsection{Construction and Characterization of $m C H T / A L G$ Multilayered Films by Quartz-Crystal Microbalance}

Alginic acid sodium salt from brown algae (Sigma-Aldrich, St. Louis, MO, USA ref. 71238) was dissolved in a solution of $\mathrm{NaCl}(0.15 \mathrm{M}$, Sigma) to obtain a final $0.1 \%(w / v)$ alginate solution. Solutions of mesyl-CHT and tosyl-CHT (all at $0.1 \% w / v$ ) were obtained by dissolving the mesyl-CHT and tosyl-CHT in a solution of $\mathrm{NaCl}(0.15 \mathrm{M})$. A solution of unmodified chitosan (here, normal-CHT) at a concentration of $0.1 \%(w / v)$ was obtained by dissolving normal-CHT in $1 \%(v / v)$ acidic acid (Sigma) followed by the addition of $\mathrm{NaCl}$ to a final concentration of $0.15 \mathrm{M}$. The $\mathrm{pH}$ of all solutions was then adjusted to $5.5 \mathrm{using} 2 \mathrm{M} \mathrm{NaOH}$ and $1 \%(v / v)$ acetic acid. Laser doppler electrophoresis is often used to measure the magnitude of the charge of colloidal suspensions, but is also appropriate to determine the polycationic and polyanionic behavior of solubilized polymeric materials. Therefore, the zeta $(\zeta)$-potential values of solutions were measured using Nano-ZS (Malvern, Worcestershire, UK), at $25^{\circ} \mathrm{C}$.

Deposition of CHT/ALG multilayers on the gold-coated crystals was monitored by a Q-Sense E4 quartz-crystal microbalance (Q-Sense AB) with dissipation monitoring system [39]. Briefly, AT-cut quartz crystal was excited at 5, 25, 35 and $45 \mathrm{MHz}$ (fundamental frequency, 5th, 7th, and 9th overtones, respectively). The initial crystal cleaning was performed in an ultrasound bath at $30{ }^{\circ} \mathrm{C}$ followed by immersion in acetone, ethanol and isopropanol. Starting with CHT solution, deposition of polyelectrolytes took place at a constant flow rate of $50 \mathrm{~mL} / \mathrm{min}, 25{ }^{\circ} \mathrm{C}$ and $\mathrm{pH} 5.5$ for $22 \mathrm{~min}$. Following the deposition of each polyelectrolyte, a rinsing step with $\mathrm{NaCl}(0.15 \mathrm{M})$ at pH 5.5 for $12 \mathrm{~min}$ was performed. Changes in frequency $(\Delta F)$ and dissipation $(\Delta D)$ were monitored in real-time.

\subsection{Estimation of the Film Thickness and Properties}

The film thickness was estimated using the Voigt-based viscoelastic model [40], integrated in QTools (version 3.1.25.604) provided by Q-Sense (Biolin Scientific, Gothenburg, Sweden). The model is represented by Equations (1) and (2).

$$
\begin{gathered}
\Delta F \approx-\frac{1}{2 \pi \rho_{0} h_{0}}\left\{\frac{\eta_{3}}{\delta_{3}}+\sum_{j=k}\left[h_{j} \rho_{j} \omega-2 h_{j}\left(\frac{\eta_{3}}{\delta_{3}}\right)^{2} \frac{\eta_{j} \omega^{2}}{\mu_{j}^{2}+\omega^{2} \eta_{j}^{2}}\right]\right\} \\
\Delta D \approx \frac{1}{2 \pi f \rho_{0} h_{0}}\left\{\frac{\eta_{3}}{\delta_{3}}+\sum_{j=k}\left[2 h_{j}\left(\frac{\eta_{3}}{\delta_{3}}\right)^{2} \frac{\mu_{j} \omega}{\mu_{j}^{2}+\omega^{2} \eta_{j}^{2}}\right]\right\}
\end{gathered}
$$

In Equations (1) and (2), $\rho_{0}$ and $h_{0}$ are the density and thickness of the quartz crystal, $k$ represents total number of thin viscoelastic layers, $\eta_{3}$ is the viscosity of the bulk liquid, $\delta_{3}$ is the viscous penetration depth of the shear wave in the bulk liquid, $\rho_{3}$ is the density of liquid, $\mu$ is the elastic shear modulus of an over layer, and $\omega$ is the angular frequency of the oscillation. Estimations were made considering a fixed solvent viscosity of $0.001 \mathrm{~Pa}$ (the same as for water) and film density of $1200 \mathrm{~kg} / \mathrm{m}^{3}$. The density of solvent was changed, by trial and error, between 1000 and $1015 \mathrm{~kg} / \mathrm{m}^{3}$ until the total error, $\chi^{2}$, was minimized. Three overtones (5th, 7 th and 9th) were used for the calculations. 


\subsection{Human Adipose Stem Cell (hASC) Culture}

To evaluate the biological performance of CHT/ALG multilayered films, cell culture studies were performed using hASCs. Human abdominal subcutaneous adipose tissue samples were obtained after informed consent from patients undergoing lipoaspiration procedure. The retrieval and transportation of the samples has been performed under a valid cooperation protocol established on 12 February 2007 by the 3B's research group and the Hospital da Prelada (Porto, Portugal), which is approved by the ethical committees of both institutions, and does not have an associated number. This protocol contains all guidelines to retrieve, transport and discard biological samples in accordance with National and European recommendations, which include the signature of an Informed consent form and a standard anonymization procedure for all samples. Isolation and process of samples were carried out within $24 \mathrm{~h}$ after surgical procedure according to a protocol previously established [41]. Isolated cells were cultured under basal condition, using minimum essential alpha medium ( $\alpha$-MEM, Sigma), supplemented with $10 \%(v / v)$ fetal bovine serum (FBS, ThermoFisher Scientific, Waltham, MA, USA) and $1 \%(v / v)$ penicillin-streptomycin, until maximum passages of three. Cell culture medium was changed $48 \mathrm{~h}$ after initial plating and every 3 days thereafter.

\subsection{Preparation of Multilayered Films for Cell Culture Studies}

Glass surfaces $\left(1.0 \mathrm{~cm}^{2}\right.$ ) were prepared from coverslips (Fisher Scientific) as substrates to build normal, mesyl and tosyl-CHT/ALG multilayered films. Glass surfaces were kept inside six-well plates (Falcon, Corning, NY, USA) and covered by solutions of CHTs and ALG (all $0.1 \%$ in aqueous solution with $\mathrm{NaCl} 0.15 \mathrm{M}$ ). LbL assembly started with CHTs solution deposition and followed by ALG solution deposition (each layer with 22 min deposition time), in a sequential manner with intermediate washing step (10 min) with $\mathrm{NaCl}(0.15 \mathrm{M})$ to prepare five bilayers of films.

To study the cytotoxicity and effect of the direct contact of mCHT layer with hASCs, an additional layer of CHTs was deposited on top of five bilayers of CHT/ALG films via LbL technique. Samples were sterilized for subsequent cell culture using exposure to UV (1 h).

\subsection{Cytotoxicity and Viability Analysis}

Glass substrates coated with mesyl, tosyl and normal-CHT/ALG multilayered films, prepared according to the previous section, were used for viability and cytotoxicity testing according to ISO 10993-5 guidelines similar to the method described elsewhere [42]. Samples were incubated in triplicate in $2 \mathrm{ml} \alpha$-MEM with $10 \%(v / v)$ FBS and $1 \%(v / v)$ penicillin-streptomycin in six-well plates at $37^{\circ} \mathrm{C}$, $5 \% \mathrm{CO}_{2}$, and fully humidified air for 3 days. The resulting mediums, enriched in lixiviates potentially released from the multilayer films, was used for cytotoxicty and viability studies. Therefore, hASCs with an initial density of $8 \times 10^{4}$ cells $/ \mathrm{cm}^{2}$ was cultured in resulting medium, in 24-well plates, for 3 days. Metabolic activity of cultured cells was determined using a MTS Cell Proliferation Assay Kit (Abcam, Cambridge, UK) at three time points (days 1, 2 and 3). The results were normalized to the negative control (fresh $\alpha$-MEM with 10\% $(v / v)$ FBS and 1\% $(v / v)$ penicillin-streptomycin) for cytotoxicity analysis and compared to the positive control medium pre-incubated with latex.

Cell viability was assessed by incubating hACSs, pre-cultured in 24-well plates with resulting mediums for 3 days, with a live/dead assay at three time points (day 1,2 and 3). In brief, the hASCs were incubated for 15 min with $150 \mu \mathrm{L}$ of calcein AM (Invitrogen, Carlsbad, CA, USA) solution $(2 \mu \mathrm{L}$ calcein/mL DMEM without phenol red) and $150 \mu \mathrm{L}$ of propidium iodide (PI, Invitrogen, Carlsbad, CA, USA) working solution ( $2 \mu \mathrm{L}$ PI stock solution, $1 \mathrm{mg} / \mathrm{mL}$ in distilled water) and finally rinsed with PBS. The cells were then immediately visualized in the dark by fluorescence microscopy (Axio Imager Z1m, Zeiss, Oberkochen, Germany). 


\subsection{Cell Adhesion Studies on $m C H T / A L G$ Multilayered Film}

Cell morphology and adhesion were assessed according to the protocol previously reported [43]. Briefly, a cell suspension of hASCs $\left(10^{6}\right.$ cells $\left./ \mathrm{mL}\right)$ was prepared using Tryple Express (ThermoScientific). Cell suspensions (passage 3-5) with the density of $2.0 \times 10^{4} \mathrm{cell} / \mathrm{cm}^{2}$ were cultured on top of glass surfaces pre-coated with five bilayers of CHT/ALG films using $\alpha$-MEM supplemented with $10 \%(v / v)$ FBS and 1\% $(v / v)$ penicillin-streptomycin in humidified atmosphere $\left(37^{\circ} \mathrm{C}, 5 \% \mathrm{CO}_{2}\right)$. After $24 \mathrm{~h}$, culture medium was removed, samples were washed with PBS and incubated with $10 \%$ of formalin at room temperature (RT) for $1 \mathrm{~h}$. Samples were washed with PBS and incubated with $0.1 \%$ Triton $X$ for 5 min at RT to permeabilize cells. Samples were washed again with PBS and solutions of 4,6-Diaminidino-2-phenylindole-dilactate (DAPI, $20 \mathrm{mg} / \mathrm{mL}$, Sigma-Aldrich) and phalloidin tetramethylrhodamine B isothiocyanate dyes (phalloidin, $10 \mathrm{mg} / \mathrm{mL}$, Sigma-Aldrich) were added to the samples to stain the nuclei and cytoskeleton F-actin of the hASCs, respectively. After $1 \mathrm{~h}$ at RT and protected from light, cells were washed three times with PBS and immediately visualized in the dark condition by reflected light fluorescence microscopy (Axio Imager Z1m, Zeisss, Oberkochen, Germany) to assess cellular adhesion, and morphology.

\subsection{Statistical Analysis}

Statistical analysis was performed by use of IBM SPSS statistics (v. 20, Chicago, IL, USA) with the use of Mann-Whitney U analysis. Differences in results were considered statistically significant at a value of $p<0.05$. Results are presented as a mean \pm standard deviation (SD).

\section{Results and Discussion}

\subsection{Synthesis and Characterization of the Mesyl-CHT and Tosyl-CHT}

The NMR characterization of mesyl-CHT polymer demonstrated that a peak corresponding to the mesyl group appears at $2.83 \mathrm{ppm}$ as a singlet (Figure 1A) which is in line with results previously described [37]. In the spectrum of the tosylated deriavative, the peaks of the aromatic ring are present at 2.39, 7.37 and $7.70 \mathrm{ppm}$ (Figure 1B). These results confirm chemoselective modification of chitosan with mesyl and tosyl groups. The results also demonstrated that water solubility can be obtained by modification of chitosan with mesyl and tosyl groups.

Since CHT and ALG polyelectrolytes are only partially charged at moderate $\mathrm{pH}$ near their $\mathrm{p} K_{\mathrm{a}} \mathrm{s}$, working $\mathrm{pH}$ and ionic strength are expected to influence film growth and properties. In this work, the $\mathrm{pH}$ of CHT was adjusted to 5.5, below its $\mathrm{p} K_{\mathrm{a}}$ value of 6.5 [44], to ensure its performance as a polycation. $\zeta$-potential values show the cationic nature of normal and modified CHTs, as well as the anionic nature of ALG (Table 1) in aqueous solution with $0.15 \mathrm{M} \mathrm{NaCl}(\mathrm{pH}=5.5)$. This ensures the existence of electrostatic interactions between CHTs and ALG in order to build LbL films. The charge sign is the same for all chitosans, thus the modification does not change the polycationic character of this polysaccharide. Nonetheless, the results obtained herein provide a qualitative indication that the magnitude of the electrostatic density among normal and modified chitosans was not affected pronouncedly (Table 1).

Table 1. $\zeta$-Potential values of CHT (0.1\%) and ALG (0.1\%) in aqueous solution with $0.15 \mathrm{M} \mathrm{NaCl}$ $(\mathrm{pH}=5.5)$.

\begin{tabular}{cc}
\hline Polyelectrolyteolyte & $\zeta$-Potentialtial \\
\hline Normal-CHT & $+20 \pm 1.3$ \\
Mesyl-CHT & $+22.3 \pm 1.6$ \\
Tosyl-CHT & $+19.8 \pm 1.1$ \\
Alginate & $-28.6 \pm 1.7$ \\
\hline
\end{tabular}



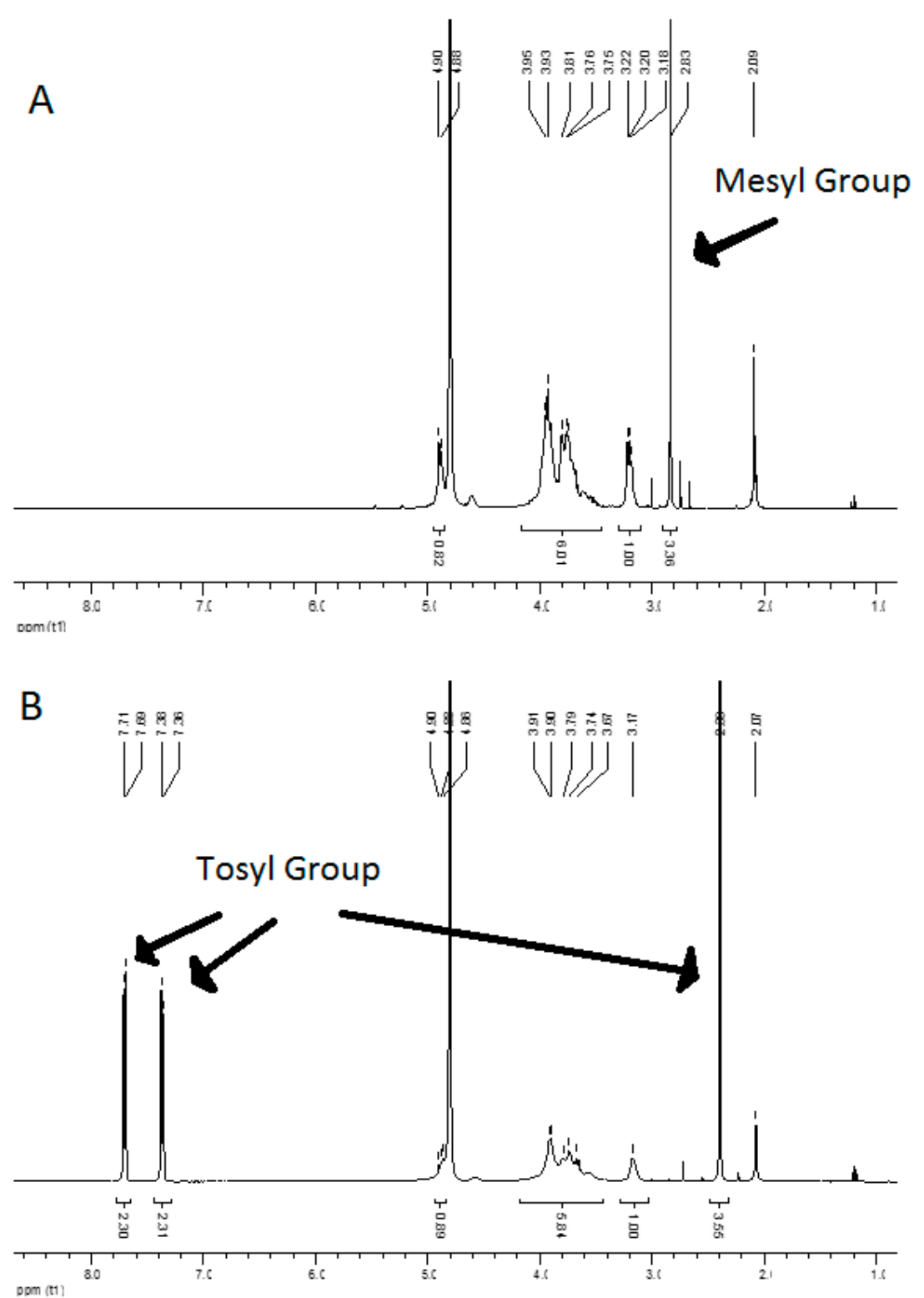

Figure 1. NMR characterization of mesyl-CHT (A) and tosyl-CHT (B). Peaks of mesyl (2.83 ppm) and tosyl groups $(2.39,7.37$ and $7.70 \mathrm{ppm})$ are highlighted by arrows.

\subsection{LbL Build-Up of $m C H T / A L G$ Multilayered Films at $p H=5.5$}

mCHT and ALG were deposited in a sequential way to build multilayered films. Cationic solutions of mCHTs were deposited on the surface of a gold-coated quartz crystal (negatively charged) and subsequently anionic solution of ALG was deposited in a similar way, with an intermediate washing step using $0.15 \mathrm{M} \mathrm{NaCl}$ buffer. Electrostatic interactions between cationic-anionic polyelectrolytes ensures the LbL buildup of multilayered films.

The LbL assembly of the CHT and ALG was monitored by a quartz microbalance with dissipation monitoring (QCM-D). QCM-D analysis proved the effective interaction between the two polyelectrolytes, chitosans and alginate, at $\mathrm{pH}$ 5.5. Therefore, it can be said that the assembly of mCHT, and normal-CHT with ALG resulted in the construction of multilayered polymeric films. Alginate, as a polyanion, interacts with the positively charged chitosan. It is assumed that the carboxylate moieties on alginate ionically interact with the protonated amine groups on chitosan to form a matrix. 
The frequency of QCM-D crystal decreases by the deposition of a thin film. The decrease in frequency $(\Delta F)$ is proportional to the mass of the film when the film is thin and rigid. However, this relation is not valid once a soft film is constructed as a result of the deposition of a polymeric material. In this situation, the energy stored in each vibrational cycle is lost and changes in dissipation $(\Delta D)$ represent a typical viscoelastic behavior. Frequency $(\Delta F)$ and dissipation $(\Delta D)$ variations normalized to the 5 th overtone during the construction of 5 bilayers are shown in Figure 2A. The decrease in frequency observed after the adsorption of each successive layers of polyelectrolytes suggests that there was a gradual growth of the polymeric films, using normal and modified chitosans. In general, dissipation values increased with time, revealing that the films are not rigid and can dissipate energy, evidencing their viscoelastic behavior (Figure $2 \mathrm{~A}$ ). $\Delta D$ provides evidence about film's viscoelastic properties in which deposition of a soft component often leads to an increase of the dissipation values due to energy loss from the crystal's oscillation, whereas smaller dissipation values are obtained for rigid components [45,46]. Using the data acquired from the QCM-D experiments, the thickness of the multilayered films was estimated using the Voigt-based viscoelastic model (Figure 2B). The assembly of CHT and ALG followed a linear regime growth (Figure 2C), resulting in films with thickness of $87.4 \pm 5.3,52.3 \pm 2.1$ and $61.2 \pm 1.4 \mathrm{~nm}$ for normal, mesyl and tosyl-CHT/ALG multilayers, respectively, after the construction of 5 bilayers. Statistical analysis demonstrated a significance difference between the thicknesses of normal-CHT/ALG and mCHT/ALG films $(p<0.05)$. Thinner $\mathrm{mCHT}$ / ALG films obtained by LbL process might be related to the presence of organic salts, mesylate and tosylate, in the chemical structure of mCHTs. The potential to make ionic interactions and form a polyelectrolyte complex (PEC) are among the important reasons that enabled the development of tailored biomaterials using ALG and CHT. The incorporation of modified chitosan in the LbL structure, with meticulous and selectivity practice, would give us the capability to control the thickness and mechanical properties of multilayered films. The possibility to change the physiochemical properties of CHT-ALG PECs by controlling the degree of association between functional groups provides an opportunity to design complex and tailored biopolymer scaffolds.
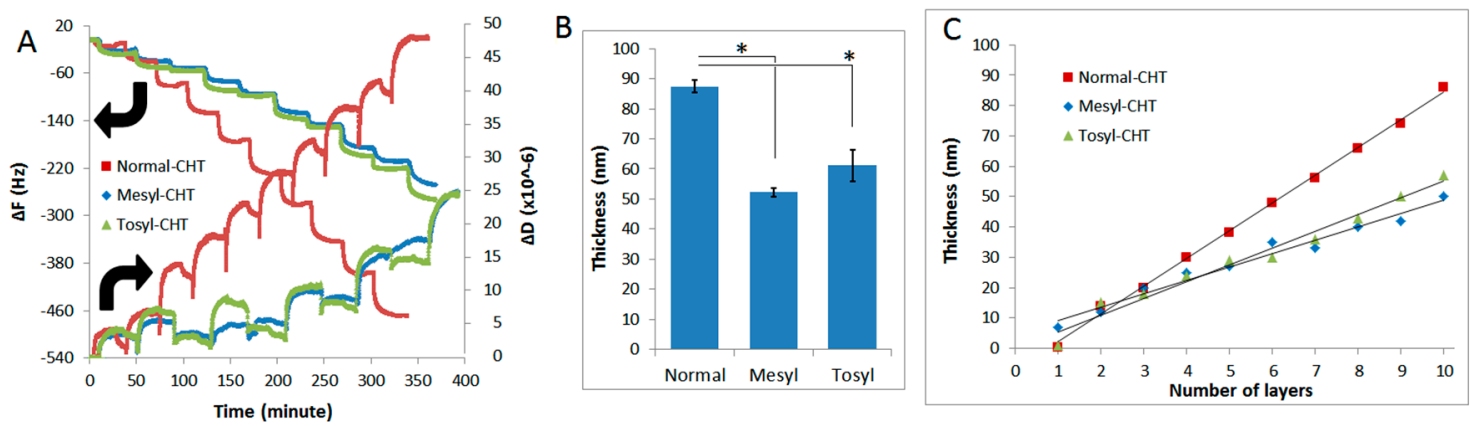

Figure 2. Representative quartz microbalance with dissipation monitoring (QCM-D) acquisition graphics depicting 5 th overtone variations of frequency (descending curves) and dissipation (ascending curves) during construction of the multilayered films using normal-CHT/alginate (ALG) (normal), mesyl-CHT/ALG (mesyl) and tosyl-CHT/ALG (tosyl) (A); Thickness of films after buildup of 5 bilayers was estimated using Voigt-based viscoelastic model (Average $\left.\pm \mathrm{SD}^{*} p<0.05\right)$ (B); Representative cumulative thickness evolution of the multilayer films as a function of the number of deposition layers. Lines represent linear trend lines with $R^{2}=0.99$ (normal-CHT), $R^{2}=0.97$ (tosyl-CHT) and $R^{2}=0.97$ (mesyl-CHT) (C).

\subsection{Cytotoxicity of $m$ CHT/ALG Multilayered Films}

In vitro studies were performed to investigate the cytotoxicity of mCHT/ALG multilayered films using hASCs. Image analysis of live/dead staining by ImageJ (V. 1.51p, Bethesda, MD, USA) displayed a uniform distribution of viable cells (as shown by cells stained with Calcein AM, in green) with viability of $96 \% \pm 4.2 \%$ cultured on top of 24 -well plate using the resulting culture medium with extract of 
mCHT/ALG films (Figure 3A). The metabolic activity of hASCs, as a result of incubating with extracts of mesyl-CHT/ALG and tosyl-CHT/ALG multilayered films, was similar to thenormal-CHT/ALG film and in the range of negative control (Figure 3B). However, the pre-incubation of the culture medium with latex resulted in lower metabolic activity and $58 \% \pm 2.3 \%$ viability of cells (Figure 3B, positive control). These results further confirmed the cytocompatibility of mCHT/ALG multilayered films for cell culture studies.
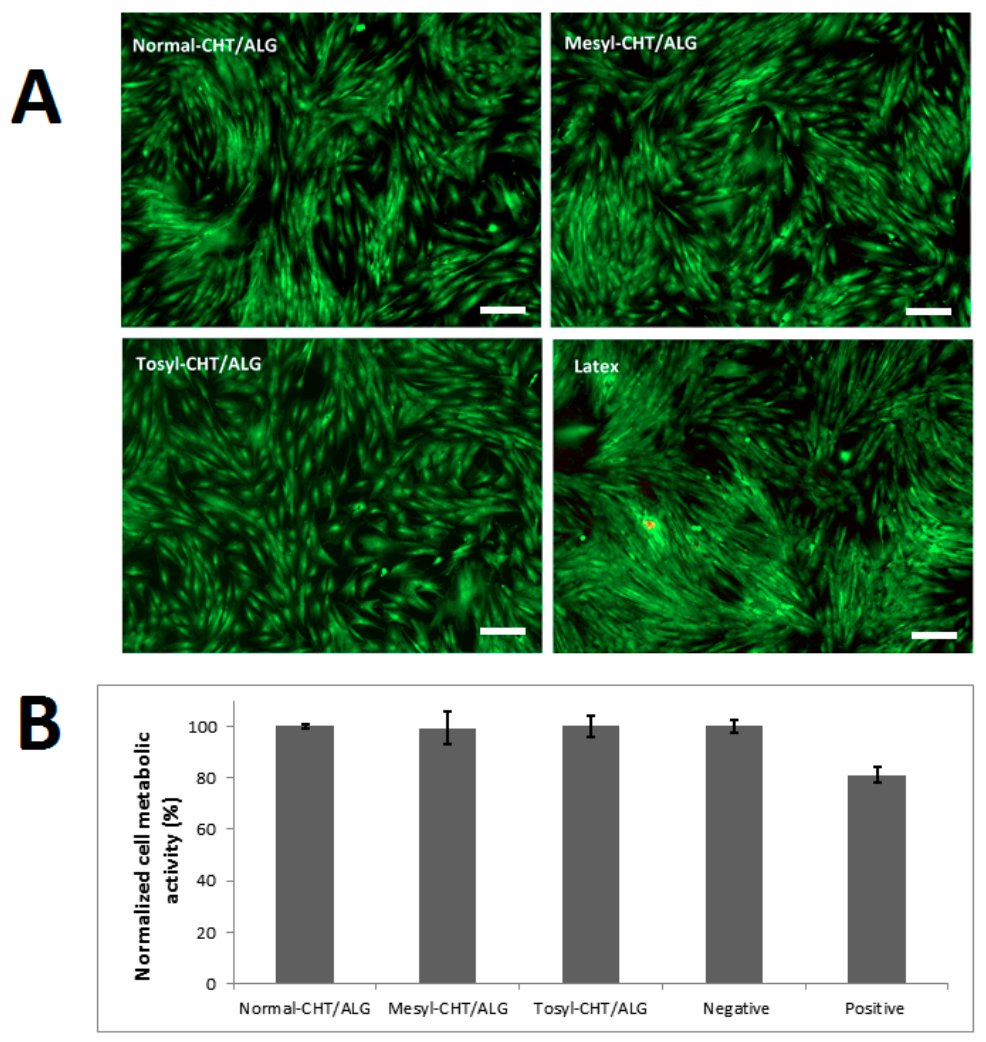

Figure 3. Representative fluorescence images of live (green) and dead (red) hASCs cultured on 24-well plates with the extract of mesyl-CHT/ALG, tosyl-CHT / ALG and normal-CHT / ALG multilayered films and latex. (A) (Scale bar $=200 \mu \mathrm{m})$; Normalized metabolic activity of hASCs was measured in contact with the extract of CHT/ALG multilayered films as well as negative (24-well plate) and positive (Latex) controls (B). Results are presented as average \pm SD.

\subsection{Aggregate Formation of hASCs on the mCHT/ALG Multilayered Films}

hACSs cultured on normal and mCHT/ALG films did not show the ability to attach and spread to the multilayered films. They assembled in the form of spheroids with sizes between ca. 100 to $200 \mu \mathrm{m}$ (Figure 4A-C). Low adhesion of the cells in such non-cytotoxic substrate can be used to stimulate cell aggregation. For example, chitosan films were used to prepare spheroids of melanocytes [47] and keratocytes [48]. In contrast, once cultured on glass substrates, hASCs exhibited common spindle shape morphology (Figure 4D). Cells need anchor points to be adhered to the substrate. Some substrates, such as tissue culture plates, are able to absorb the adhesion-related proteins, such as fibronectin, and this allows the attachment of cells to that specific substrate [49,50]. It was previously reported that the amount of adhesive-related proteins was far less in chitosan compared to tissue culture substrates [51]. This result may be attributed to the monopolar nature of chitosan, which is not able to interact with the bipolar extracellular matrix proteins presented in the culture medium. Our result also corroborates previous findings that non-crosslinked free standing CHT/ALG multilayered membranes could not support the adhesion of L929 cells [23]. One could also envisage using the developed multilayers as 
reservoirs of bioactive agents that could also extend the applicability of these substrates as supports to control cell behavior [52].
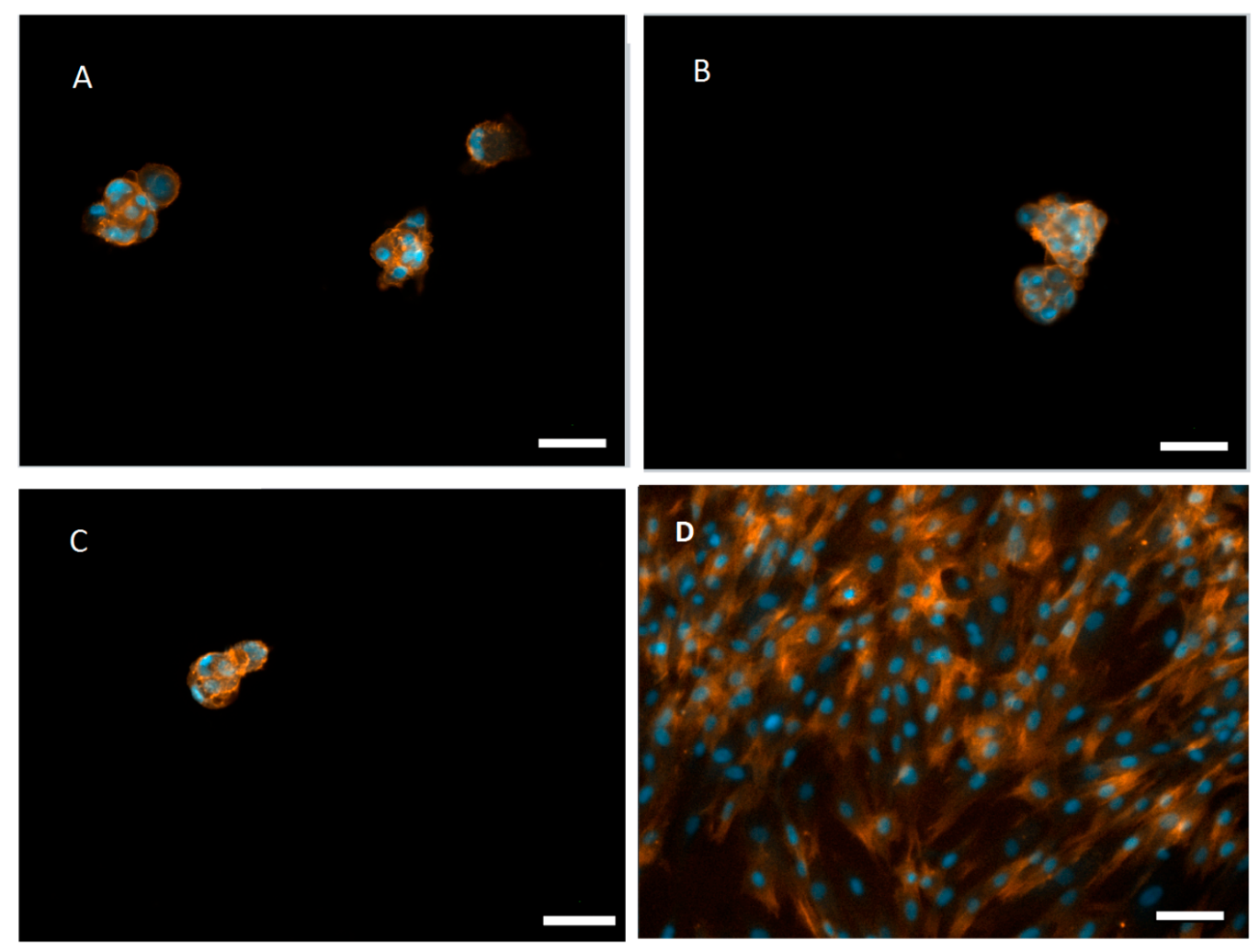

Figure 4. Representative fluorescence images of the hASCs cultured on top of normal-CHT/ALG (A); mesyl-CHT /ALG (B); tosyl-CHT/ALG (C); multilayered films and glass substrate (D). Multilayered films included subsequent layers of CHT and ALG with top layer (11th layer) was CHT. Scale bar: $200 \mu \mathrm{m}$. Cell nuclei appeared bright blue and F-actin filaments appeared bright red due to DAPI and phalloidin dyes, respectively.

\section{Conclusions}

Chitosan and alginate are two natural-based polymers with proved application in developing biomaterials for tissue engineering and regenerative medicine. In this study, we suggest the use of multilayered film produced by LbL assembly of modified chitosan/alginate as a scaffold to produce 3D aggregates of hASCs. We investigated how the modification of chitosan could affect the mCHT/ALG film properties and the corresponding biological performance. Therefore, two water-soluble cationic derivatives of chitosan, namely mesyl and tosyl chitosans, were synthesized and nanostructured multilayered LbL films were created using ALG as an anionic polyelectrolyte. mCHT/ALG films showed lower thickness compared to the normal-CHT/ALG films. Therefore, modification of chitosan with organic salts provided the ability to tailor the physiochemical properties of the multilayered films. The result demonstrated mCHT/ALG multilayered films could be used as a platform to produce 3D aggregates of hACSs. This approach may offer a new route to prepare off-the-shelf chitosan products which have the advantage of solubility in water at a neutral $\mathrm{pH}$, and may be used for customizing the properties of films without the adjustment of processing parameters. Moreover, one could envisage incorporating biological signals in the multilayer films for a variety of applications, such as controlling the behavior of cells. It would be important to further investigate the effect of multilayer properties and spheroid formation on the differentiation potential and stemness of hACSs. This information is useful to develop tailored biomaterials to regulate the function and behavior of hACSs for varieties of applications in tissue engineering and regenerative medicine. 
Acknowledgments: This paper was partially financed by the ELASTISLET H2020-NMP-2014-646075 project, Fundo Social Europeu (FSE) and Programa Operacional de Potencial Humano (POPH). Javad Hatami, Rui R. Costa and Mariana B. Oliveira acknowledge the Fundação para a Ciência e Tecnologia (FCT) for grants SFRH/BPD/117202/2016, SFRH/BPD/95446/2013 and SFRH/BPD/111354/2015, respectively. Sandra G. Silva acknowledges the grant from ComplexiTE project.

Author Contributions: Javad Hatami, Sandra G. Silva, Mariana B. Oliveira, Rui R. Costa and João F. Mano conceived and designed the experiments; Javad Hatami and Sandra G. Silva performed the experiments; Javad Hatami, Sandra G. Silva, Mariana B. Oliveira, Rui R. Costa, Rui L. Reis and João F. Mano analyzed the data, wrote and revised the paper.

Conflicts of Interest: The authors declare no conflict of interest. The founding sponsors had no role in the design of the study; in the collection, analyses, or interpretation of data; in the writing of the manuscript, and in the decision to publish the results.

\section{References}

1. Gimble, M.J.; Guilak, F. Differentiation potential of adipose derived adult stem (ADAS) cells. Curr. Top. Dev. Biol. 2003, 58, 137-160. [PubMed]

2. Guilak, F.; Lott, K.E.; Awad, H.A.; Cao, Q.; Hicok, K.C.; Fermor, B.; Gimble, J.M. Clonal analysis of the differentiation potential of human adipose-derived adult stem cells. J. Cell Physiol. 2006, 206, $229-237$. [CrossRef] [PubMed]

3. Jones, L.D.; Wagers, A.J. No place like home: Anatomy and function of the stem cell niche. Nat. Rev. Mol. Cell Biol. 2008, 9, 11-21. [CrossRef] [PubMed]

4. Frith, J.E.; Thomson, B.; Genever, P.G. Dynamic three-dimensional culture methods enhance mesenchymal stem cell properties and increase therapeutic potential. Tissue Eng. C 2010, 16, 735-749. [CrossRef] [PubMed]

5. Bartosh, T.J.; Ylöstalo, J.H.; Mohammadipoor, A.; Bazhanov, N.; Coble, K.; Claypool, K.; Lee, R.H.; Choi, H.; Prockop, D.J. Aggregation of human mesenchymal stromal cells (MSCs) into 3D spheroids enhances their antiinflammatory properties. Proc. Natl. Acad. Sci. USA 2010, 107, 13724-13729. [CrossRef] [PubMed]

6. Wang, W.; Itaka, K.; Ohba, S.; Nishiyama, N.; Chung, U.I.; Yamasaki, Y.; Kataoka, K. 3D spheroid culture system on micropatterned substrates for improved differentiation efficiency of multipotent mesenchymal stem cells. Biomaterials 2009, 30, 2705-2715. [CrossRef] [PubMed]

7. Oliveira, M.B.; Neto, A.I.; Correia, C.R.; Rial-Hermida, M.I.; Alvarez-Lorenzo, C.; Mano, J.F. Superhydrophobic chips for cell spheroids high-throughput generation and drug screening. ACS Appl. Mater. Interfaces 2014, 6, 9488-9495. [CrossRef] [PubMed]

8. Borges, J.; Mano, J.F. Molecular Interactions Driving the Layer-by-Layer Assembly of Multilayers. Chem. Rev. 2014, 114, 8883-8942. [CrossRef] [PubMed]

9. Richardson, J.J.; Björnmalm, M.; Caruso, F. Technology-driven layer-by-layer assembly of nanofilms. Science 2015, 348. [CrossRef] [PubMed]

10. Xiao, F.X.; Pagliaro, M.; Xu, Y.J.; Liu, B. Layer-by-layer assembly of versatile nanoarchitectures with diverse dimensionality: A new perspective for rational construction of multilayer assemblies. Chem. Soc. Rev. 2016, 45, 3088-3121. [CrossRef] [PubMed]

11. Costa, R.R.; Mano, J.F. Polyelectrolyte multilayered assemblies in biomedical technologies. Chem. Soc. Rev. 2014, 43, 3453-3479. [CrossRef] [PubMed]

12. Oliveira, M.B.; Hatami, J.; Mano, J.F. Coating Strategies Using Layer-by-layer Deposition for Cell Encapsulation. Chem. Asian J. 2016, 11, 1753-1764. [CrossRef] [PubMed]

13. Boudou, T.; Crouzier, T.; Ren, K.; Blin, G.; Picart, C. Multiple Functionalities of Polyelectrolyte Multilayer Films: New Biomedical Applications. Adv. Mater. 2010, 22, 441-467. [CrossRef] [PubMed]

14. Joseph, N.; Ahmadiannamini, P.; Hoogenboom, R.; Vankelecom, I.F. Layer-by-layer preparation of polyelectrolyte multilayer membranes for separation. Polym. Chem. 2014, 5, 1817-1831. [CrossRef]

15. Banik, B.L.; Brown, J.L. Chapter 23-Polymeric Biomaterials in Nanomedicine A2-Kumbar, Sangamesh G. In Natural and Synthetic Biomedical Polymers; Laurencin, C.T., Deng, M., Eds.; Elsevier: Oxford, UK, 2014; pp. 387-395. 
16. Mano, J.F.; Silva, G.A.; Azevedo, H.S.; Malafaya, P.B.; Sousa, R.A.; Silva, S.S.; Boesel, L.F.; Oliveira, J.M.; Santos, T.C.; Marques, A.P.; et al. Natural origin biodegradable systems in tissue engineering and regenerative medicine: Present status and some moving trends. J. R. Soc. Interface 2007, 4, 999-1030. [CrossRef] [PubMed]

17. Hynes, R.O. The Extracellular Matrix: Not Just Pretty Fibrils. Science 2009, 326, 1216-1219. [CrossRef] [PubMed]

18. Finkenstadt, V.L. Natural polysaccharides as electroactive polymers. Appl. Microbiol. Biotechnol. 2005, 67, 735-745. [CrossRef] [PubMed]

19. Cardoso, M.J.; Costa, R.R.; Mano, J.F. Marine Origin Polysaccharides in Drug Delivery Systems. Mar. Drugs 2016, 14. [CrossRef] [PubMed]

20. Basu, A.; Kunduru, K.R.; Abtew, E.; Domb, A.J. Polysaccharide-Based Conjugates for Biomedical Applications. Bioconjug. Chem. 2015, 26, 1396-1412. [CrossRef] [PubMed]

21. Senni, K.; Pereira, J.; Gueniche, F.; Delbarre-Ladrat, C.; Sinquin, C.; Ratiskol, J.; Godeau, G.; Fischer, A.M.; Helley, D.; Colliec-Jouault, S. Marine Polysaccharides: A Source of Bioactive Molecules for Cell Therapy and Tissue Engineering. Mar. Drugs 2011, 9, 1664-1681. [CrossRef] [PubMed]

22. Oliveira, S.M.; Santo, V.E.; Gomes, M.E.; Reis, R.L.; Mano, J.F. Layer-by-layer assembled cell instructive nanocoatings containing platelet lysate. Biomaterials 2015, 48, 56-65. [CrossRef] [PubMed]

23. Silva, J.M.; Duarte, A.R.C.; Caridade, S.G.; Picart, C.; Reis, R.L.; Mano, J.F. Tailored Freestanding Multilayered Membranes Based on Chitosan and Alginate. Biomacromolecules 2014, 15, 3817-3826. [CrossRef] [PubMed]

24. Caridade, S.G.; Monge, C.; Gilde, F.; Boudou, T.; Mano, J.F.; Picart, C. Free-Standing Polyelectrolyte Membranes Made of Chitosan and Alginate. Biomacromolecules 2013, 14, 1653-1660. [CrossRef] [PubMed]

25. Cuomo, F.; Lopez, F.; Miguel, M.G. Vesicle-templated layer-by-layer assembly for the production of nanocapsules. Langmuir 2010, 26, 10555-10560. [CrossRef] [PubMed]

26. Correia, C.R.; Pirraco, R.P.; Cerqueira, M.T.; Marques, A.P.; Reis, R.L.; Mano, J.F. Semipermeable Capsules Wrapping a Multifunctional and Self-regulated Co-culture Microenvironment for Osteogenic Differentiation. Sci. Rep. 2016, 6, 21883. [CrossRef] [PubMed]

27. Lee, K.Y.; Mooney, D.J. Alginate: Properties and biomedical applications. Prog. Polym. Sci. 2012, 37, $106-126$. [CrossRef] [PubMed]

28. Vegas, A.J.; Veiseh, O.; Gürtler, M.; Millman, J.R.; Pagliuca, F.W.; Bader, A.R.; Doloff, J.C.; Li, J.; Chen, M.; Olejnik, K.; et al. Long-term glycemic control using polymer-encapsulated human stem cell-derived beta cells in immune-competent mice. Nat. Med. 2016, 22, 306-311. [CrossRef] [PubMed]

29. Rinaudo, M. Chitin and chitosan: Properties and applications. Prog. Polym. Sci. 2006, 31, 603-632. [CrossRef]

30. Francis Suh, J.K.; Matthew, H.W.T. Application of chitosan-based polysaccharide biomaterials in cartilage tissue engineering: A review. Biomaterials 2000, 21, 2589-2598. [CrossRef]

31. Wang, Z.; Zhang, X.; Gu, J.; Yang, H.; Nie, J.; Ma, G. Electrodeposition of alginate/chitosan layer-by-layer composite coatings on titanium substrates. Carbohydr. Polym. 2014, 103, 38-45. [CrossRef] [PubMed]

32. Silva, J.M.; Duarte, A.R.C.; Custódio, C.A.; Sher, P.; Neto, A.I.; Pinho, A.; Fonseca, J.; Reis, R.L.; Mano, J.F. Nanostructured Hollow Tubes Based on Chitosan and Alginate Multilayers. Adv. Healthc. Mater. 2014, 3, 433-440. [CrossRef] [PubMed]

33. Zhao, Q.; Han, B.; Wang, Z.; Gao, C.; Peng, C.; Shen, J. Hollow chitosan-alginate multilayer microcapsules as drug delivery vehicle: Doxorubicin loading and in vitro and in vivo studies. Nanomed. Nanotechnol. Biol. Med. 2007, 3, 63-74. [CrossRef] [PubMed]

34. Martins, G.V.; Mano, J.F.; Alves, N.M. Nanostructured self-assembled films containing chitosan fabricated at neutral pH. Carbohydr. Polym. 2010, 80, 570-573. [CrossRef]

35. Rúnarsson, Ö.V.; Malainer, C.; Holappa, J.; Sigurdsson, S.T.; Másson, M. tert-Butyldimethylsilyl O-protected chitosan and chitooligosaccharides: Useful precursors for N-modifications in common organic solvents. Carbohydr. Res. 2008, 343, 2576-2582. [CrossRef] [PubMed]

36. Song, W.; Gaware, V.S.; Rúnarsson, Ö.V.; Másson, M.; Mano, J.F. Functionalized superhydrophobic biomimetic chitosan-based films. Carbohydr. Polym. 2010, 81, 140-144. [CrossRef]

37. Sahariah, P.; Gaware, V.S.; Lieder, R.; Jónsdóttir, S.; Hjálmarsdóttir, M.Á.; Sigurjonsson, O.E.; Másson, M. The Effect of Substituent, Degree of Acetylation and Positioning of the Cationic Charge on the Antibacterial Activity of Quaternary Chitosan Derivatives. Mar. Drugs 2014, 12, 4635-4658. [CrossRef] [PubMed] 
38. Signini, R.; Campana, S.P. On the preparation and characterization of chitosan hydrochloride. Polym. Bull. 1999, 42, 159-166. [CrossRef]

39. Costa, R.R.; Custódio, C.A.; Arias, F.J.; Rodríguez-Cabello, J.C.; Mano, J.F. Layer-by-Layer Assembly of Chitosan and Recombinant Biopolymers into Biomimetic Coatings with Multiple Stimuli-Responsive Properties. Small 2011, 7, 2640-2649. [CrossRef] [PubMed]

40. Voinova, M.V.; Rodahl, M.; Jonson, M.; Kasemo, B. Viscoelastic acoustic response of layered polymer films at fluid-solid interfaces: Continuum mechanics approach. Phys. Scr. 1999, 59, 391-399. [CrossRef]

41. Cerqueira, M.T.; Pirraco, R.P.; Santos, T.C.; Rodrigues, D.B.; Frias, A.M.; Martins, A.R.; Reis, R.L.; Marques, A.P. Human adipose stem cells cell sheet constructs impact epidermal morphogenesis in full-thickness excisional wounds. Biomacromolecules 2013, 14, 3997-4008. [CrossRef] [PubMed]

42. Poursamar, S.A.; Hatami, J.; Lehner, A.N.; da Silva, C.L.; Ferreira, F.C.; Antunes, A.P.M. Gelatin porous scaffolds fabricated using a modified gas foaming technique: Characterisation and cytotoxicity assessment. Mater. Sci. Eng. C 2015, 48, 63-70. [CrossRef] [PubMed]

43. Oliveira, M.B.; Custódio, C.A.; Gasperini, L.; Reis, R.L.; Mano, J.F. Autonomous osteogenic differentiation of hASCs encapsulated in methacrylated gellan-gum hydrogels. Acta Biomater. 2016, 41, 119-132. [CrossRef] [PubMed]

44. Younes, I.; Rinaudo, M. Chitin and chitosan preparation from marine sources. Structure, properties and applications. Mar. Drugs 2015, 13, 1133-1174. [CrossRef] [PubMed]

45. Cho, N.J.; Kanazawa, K.K.; Glenn, J.S.; Frank, C.W. Employing two different quartz crystal microbalance models to study changes in viscoelastic behavior upon transformation of lipid vesicles to a bilayer on a gold surface. Anal. Chem. 2007, 79, 7027-7035. [CrossRef] [PubMed]

46. Höök, F.; Kasemo, B.; Nylander, T.; Fant, C.; Sott, K.; Elwing, H. Variations in coupled water, viscoelastic properties, and film thickness of a Mefp-1 protein film during adsorption and cross-linking: A quartz crystal microbalance with dissipation monitoring, ellipsometry, and surface plasmon resonance study. Anal. Chem. 2001, 73, 5796-5804. [CrossRef] [PubMed]

47. Lin, S.J.; Jee, S.H.; Hsaio, W.C.; Lee, S.J.; Young, T.H. Formation of melanocyte spheroids on the chitosan-coated surface. Biomaterials 2005, 26, 1413-1422. [CrossRef] [PubMed]

48. Chen, Y.H.; Wang, I.J.; Young, T.H. Formation of keratocyte spheroids on chitosan-coated surface can maintain keratocyte phenotypes. Tissue Eng. A 2009, 15, 2001-2013. [CrossRef] [PubMed]

49. Neto, A.I.; Vasconcelos, N.L.; Oliveira, S.M.; Ruiz-Molina, D.; Mano, J.F. High-Throughput Topographic, Mechanical, and Biological Screening of Multilayer Films Containing Mussel-Inspired Biopolymers. Adv. Funct. Mater. 2016, 26, 2745-2755. [CrossRef]

50. Caridade, S.G.; Monge, C.; Almodóvar, J.; Guillot, R.; Lavaud, J.; Josserand, V.; Coll, J.L.; Mano, J.F.; Picart, C. Myoconductive and osteoinductive free-standing polysaccharide membranes. Acta Biomater. 2015, 15, 139-149. [CrossRef] [PubMed]

51. Cuy, J.L.; Beckstead, B.L.; Brown, C.D.; Hoffman, A.S.; Giachelli, C.M. Adhesive protein interactions with chitosan: Consequences for valve endothelial cell growth on tissue-engineering materials. J. Biomed. Mater. Res. A 2003, 67, 538-547. [CrossRef] [PubMed]

52. Costa, R.R.; Alatorre-Meda, M.; Mano, J.F. Drug nano-reservoirs synthesized using layer-by-layer technologies. Biotechnol. Adv. 2015, 33, 1310-1326. [CrossRef] [PubMed]

(C) 2017 by the authors. Licensee MDPI, Basel, Switzerland. This article is an open access article distributed under the terms and conditions of the Creative Commons Attribution (CC BY) license (http://creativecommons.org/licenses/by/4.0/). 